\title{
Late mortality in elderly patients surviving acute peptic ulcer bleeding
}

\author{
N Hudson, G Faulkner, S J Smith, M J S Langman, C J Hawkey, R F A Logan
}

\begin{abstract}
Acute peptic ulcer bleeding is associated with a substantial short term mortality but it is generally assumed that in the modern era of effective medical treatment the longer term prognosis is good. This study evaluated 487 patients aged over 60 years who were discharged from Nottingham University and City Hospitals after admission for acute peptic ulcer bleeding during 1986-91 and 480 age and sex matched community controls. Follow up information was obtained from hospital and general practitioner records and from the National Health Service central register. Mortality was compared with control mortality and with rates expected for England and Wales. During a mean follow up of 34 months $142(29 \%)$ of 487 patients died compared with $58(12 \%)$ of 480 community controls and with 81.5 deaths expected (observed/expected $(\mathrm{O} / \mathrm{E})=1.74,95 \%$ confidence limits (CL)
\end{abstract} 1.5 to $2 \cdot 1)$. Six years after admission the actuarial survival estimate was only $\mathbf{5 0 \%}$ for ulcer patients compared with $76 \%$ for community controls and $69 \%$ expected. The increased mortality was similar in men and women and was greatest in the 60-74 year age group. Much of the excess mortality was accounted for by deaths from cancer $(O / E$ 34/19.7=1.73; CL $1 \cdot 2$ to 2.4), from respiratory disease (O/E 28/10.9=2.57; CL 1.7 to 3.7), and in men from vascular disease $(\mathrm{O} / \mathrm{E} 31 / 22 \cdot 4=1 \cdot 38$; CL 0.9 to $2 \cdot 0$ ). Eight deaths resulted from recurrent ulcer complications and four deaths from gastric cancers undetected at the index admission. In conclusion, patients discharged after peptic ulcer bleeding had a substantially reduced life expectancy. The increased mortality was predominantly due to a variety of smoking related diseases rather than recurrent peptic ulcer complications. Deaths from recurrent peptic ulcer complications were infrequent and were less than reported in earlier years possibly reflecting prolonged and widespread use of $\mathrm{H}_{2}$ receptor antagonists.

(Gut 1995; 37: 177-181)

Keywords: peptic ulcer, non-aspirin, anti-inflammatory drugs, upper gastrointestinal haemorrhage.

Acutely bleeding peptic ulcers are associated with hospital mortality of between 4 and $14 \% .{ }^{1-4}$ About a half of these bleeds occur in users of non-steroidal anti-inflammatory drugs (NSAIDs) whether aspirin or non-aspirin. In the past the subsequent morbidity and mortality related to peptic ulcer disease was considerable but this morbidity may now have diminished because of general changes in patterns of treatment (see accompanying paper). The current life expectancy of patients with bleeding ulcers and their mode of death is thus unclear. Similarly it is not known whether subsequent survival varies according to NSAID use. We have therefore investigated the mortality experience of a cohort of elderly patients presenting with an acute bleeding peptic ulcer.

\section{Patients and methods}

As described in the accompanying paper all patients aged 60 years or over admitted to the Nottingham University and City Hospitals between April 1986 and January 1991 with a bleeding peptic ulcer were considered for inclusion (Table I). Acute upper gastrointestinal haemorrhage was defined as haematemesis or melaena, or both, or collapse subsequently found either at endoscopy or surgery to be caused by bleeding peptic ulceration. As this was part of a case control study patients were interviewed shortly after admission by a trained interviewer (GF) using a structured eight page questionnaire covering personal details, medical history, and drug use. ${ }^{5}$ For each patient an age and sex matched community control was chosen by visiting the general practice with whom the case was registered. This was done by either choosing the next patient on the age sex register (within two years of age) or drawing the next record from the files similarly matched. Control subjects were then interviewed at home by the same interviewer within two months of the patient's hospital admission. For all subjects consent was obtained before interview. The subsequent outcome in patients who were alive 30 days after admission and the community controls was determined in January 1992 with

TABLE I Source of case and control cohorts

\begin{tabular}{lcc}
\hline & Cases & Controls \\
\hline Cases identified & 648 & 0 \\
Subjects interviewed (n) & 500 & 0 \\
Controls matched & 0 & 500 \\
Died within 30 days of admission & 13 & 0 \\
Subjects analysed (n) & 487 & 480 \\
Not interviewed & 148 & 20 \\
Died before interview possible & 73 & 0 \\
Confused/unable to reply clearly & 26 & 0 \\
Refused & 2 & 20 \\
Language difficulties & 7 & 0 \\
Interviewer unavailable & 40 & 0 \\
\hline
\end{tabular}


TABLE II Comparability of patients and community control cohorts

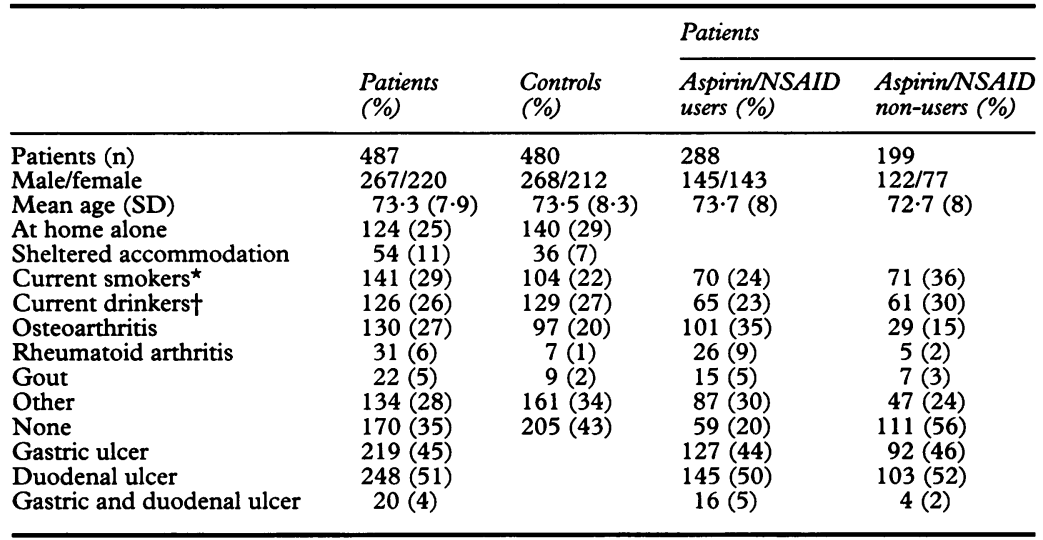

${ }^{\star}$ Defined as smoking at least one cigarette/day; †defined as drinking seven + units of alcohol/week. reference to survival, date, and cause of death. Information was obtained from hospital and general practitioner records, and death certificate information obtained from the Nottinghamshire FHSA and from the NHS central register in Southport. Follow up data were available for all patients and all but four community controls.

Statistical analysis was performed according to each patient's and community control's previous drug intake; comparisons were made between users and non-users of NSAIDs and of other groups of drugs. Relative risk estimates were crude odds ratio calculations as obtained by the methods of Mantel and Haenszel. ${ }^{6}$ Expected deaths were calculated using the 1989 death rates for England and Wales ${ }^{7}$ applied to the cumulative person years at risk for cases and controls. Person years at risk were calculated using a standard cohort analysis program ${ }^{8}$ and actuarial survival curves were plotted using the death rates obtained from this analysis. For comparisons of NSAID users and non-users a Cox proportional hazards analysis was performed using EGRET to adjust for any differences in age, sex, and smoking habit. ${ }^{910}$ All probability values were two tailed.

\section{Results}

As Table I shows 500 of 648 patients aged 60 or over with a bleeding peptic ulcer were interviewed. Thirteen patients subsequently died within 30 days of admission. Of 500 community controls approached 480 consented to interview.

TABLE III Previous drug use in patients with bleeding ulcers and community control cohorts

\begin{tabular}{|c|c|c|c|}
\hline & $\begin{array}{l}\text { Patients (\%) } \\
(n=487)\end{array}$ & $\begin{array}{l}\text { Controls (\%) } \\
(n=480)\end{array}$ & $\begin{array}{l}\text { Crude odds ratio } \\
(95 \% C L)\end{array}$ \\
\hline $\begin{array}{l}\text { Any NSAID } \\
\text { Other analgesics } \\
\text { Antacids } \\
\text { Antiulcer } \\
\text { Diuretics } \\
\text { Corticosteroids } \\
\text { Anticoagulants } \\
\text { Antiarrhythmics/ } \beta \text { blockers } \\
\text { Antihypertensives } \\
\text { Bronchodilators } \\
\text { Antidiabetic }\end{array}$ & $\begin{array}{l}288(59) \\
380(78) \\
164(34) \\
76(16) \\
167(34) \\
20(4) \\
22(5) \\
33(7) \\
82(17) \\
67(14) \\
18(4)\end{array}$ & $\begin{array}{l}161(34) \\
283(59) \\
78(16) \\
18(4) \\
91(19) \\
10(2) \\
3(1) \\
51(11) \\
71(15) \\
63(13) \\
3(1)\end{array}$ & $\begin{array}{l}2.87(2.2 \text { to } 3.7) \\
2.47(1.8 \text { to } 3.3) \\
2.62(1.9 \text { to } 3.6) \\
4.75(2.8 \text { to } 8 \cdot 1) \\
2.23(1.7 \text { to } 3.0) \\
2.01(0.9 \text { to } 4.4) \\
7.52(2.2 \text { to } 2.5) \\
0.61(0.4 \text { to } 1.0) \\
1.17(0.8 \text { to } 1.7) \\
1.06(0.7 \text { to } 1.5) \\
6.23(1.8 \text { to } 2 \cdot 1)\end{array}$ \\
\hline
\end{tabular}

\section{Comparability of patients and controls}

Patients and their controls were well matched for age and sex. Controls were slightly healthier and more independent than the patients as shown by their lower prevalence of smoking, self reported osteoarthritis and rheumatoid arthritis, and living in sheltered accommodation. Table II shows these and other characteristics of the two groups. Gastric ulceration occurred in $45 \%$ of patients and duodenal ulceration in $51 \%$. Men were significantly more likely to have duodenal ulcers than women. NSAID use did not seem to influence the site of ulceration, being duodenal in about a half of users and non-users (Table II).

\section{Drug treatment of patients and controls}

Compared with control subjects, patients with bleeding ulcers were significantly more likely to be taking NSAIDs of all types, antacids, antiulcer drugs, corticosteroids, anticoagulants, diuretics, and antidiabetic drugs and less likely to be taking antiarrhythmic or $\beta$ blocker drugs (Table III). Among the patients, those who were taking aspirin or other NSAIDs at the time of admission were also significantly less likely than patients not receiving these drugs to be taking antacids $(30 \% v 39 \%)$ or antiulcer drugs ( $11 \%$ v $22 \%$ ), although use of both these classes of drugs was higher in each subgroup than in control subjects. The increased use of diuretics in the bleeding ulcer patients was largely confined to patients taking aspirin or other NSAIDs with $122(42 \%)$ of NSAID users reporting diuretic use compared with 45 $(23 \%)$ of non-users.

\section{Death rates}

Of the 487 patients $142(29 \%)$ died in the follow up period (mean duration 34.2 months) compared with $57(12 \%)$ of the community control group. All cause mortality was $74 \%$ greater than expected based on England and Wales death rates (O/E: $142 / 81 \cdot 5=1 \cdot 74,95 \%$ CL 1.5 to $2 \cdot 1, \mathrm{p}<0 \cdot 001$ ). In contrast the community control group's mortality was a third less than the expected (O/E $55 / 89 \cdot 5=0.61$, $95 \%$ CL $0.5-0.8, \mathrm{p}<0.001)$. All subsequent comparisons are therefore with national death rates (Fig 1).

As Table IV shows, the increase in late mortality after ulcer bleeding was similar in men and women and was not accounted for by increased mortality in the very elderly. Indeed the mortality increase tended to be greater in the younger age groups (for those $<75$ years $\mathrm{O} / \mathrm{E}=2 \cdot 7,95 \% \mathrm{CL} 2 \cdot 0$ to $3 \cdot 5$ versus $\mathrm{O} / \mathrm{E}=1 \cdot 5$, $95 \%$ CL 1.2 to 1.8 for those $>75$ years). The increase was also not confined to the year after admission with ulcer bleeding but was as great three or more years after admission.

When analysed by underlying cause of death (as stated on the death certificate) the greatest mortality increases were seen for respiratory diseases $(\mathrm{O} / \mathrm{E}=2.57,95 \% \mathrm{CL} 1.7$ to 3.7 , $\mathrm{p}<0.0001)$, and for cancer $(\mathrm{O} / \mathrm{E}=1 \cdot 73,95 \%$ CL 1.2 to $2 \cdot 4, p<0.01$ ). The second group includes four deaths (expected 1.3) from 


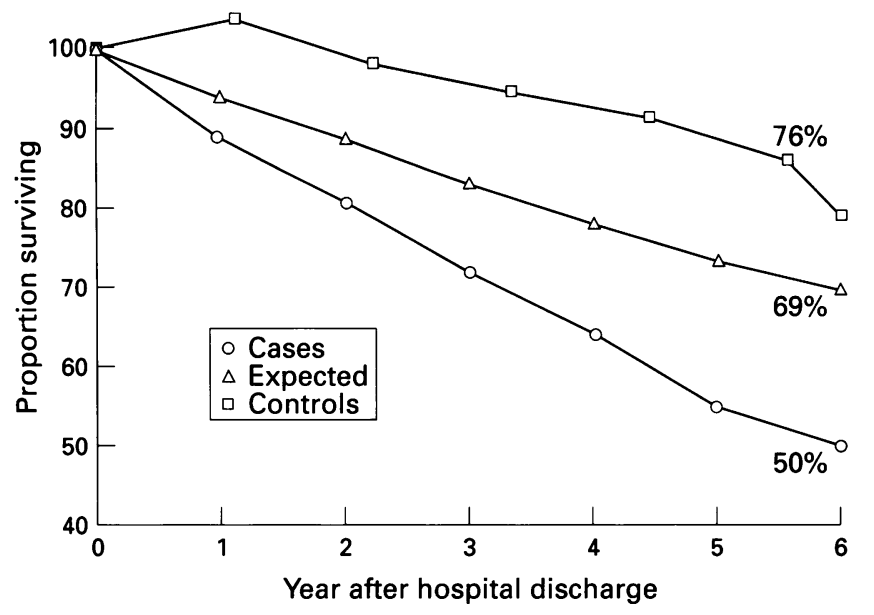

$\begin{array}{lllllll}\text { Cases/Deaths } & 487 / 51 & 435 / 35 & 326 / 27 & 194 / 17 & 101 / 10 & 49 / 2 \\ \text { Controls/Deaths } & 480 / 14 & 465 / 22 & 329 / 8 & 194 / 5 & 112 / 5 & 45 / 1\end{array}$

Figure 1: Actuarial survival curves of 487 cases following hospital discharge for peptic ulcer bleeding compared with 480 community control cohorts and national death rates for England and Wales 1989.
After adjusting for age, sex, and smoking habits the use of aspirin or other NSAIDs before the initial bleed was not associated with a greater risk of subsequent death when compared with patients not using these drugs (adjusted hazard ratio $1 \cdot 19,95 \%$ CL 0.9 to $1 \cdot 7)$.

\section{Ulcer related deaths}

Eight patients died of ulcer complications ( 3 of 288 NSAID users and 5 of 199 non-users) compared with 0.66 deaths expected from the national mortality statistics. In two of these patients death was postoperative and ulcer complications were not given as the underlying cause on the death certificate; both patients had presented with duodenal ulcer perforation six weeks and 13 months after their index bleed. Six patients suffered upper gastrointestinal bleeding one to six years after the original admission and in five death was correctly certified as being caused by duodenal or peptic ulcer and in one by gastrointestinal haemorrhage only. Five of these eight patients had not been taking $\mathrm{H}_{2}$ antagonist treatment and a further patient had $\mathrm{H}_{2}$ treatment withdrawn two weeks before admission. One of the patients who died of recurrent bleeding peptic ulceration was taking low dose $(75 \mathrm{mg})$ aspirin at the time. (2), uterus (1), bladder (1), lymphoma (2) and liver or site unspecified (5). There was a moderate increase in mortality from all vascular disease, which was only seen in men and fell short of statistical significance. There was no increase in mortality from cerebrovascular disease in either sex $(\mathrm{O} / \mathrm{E}=11 / 10 \cdot 5,95 \% \mathrm{CL}$ 0.5 to 1.9 ).

\section{Association of NSAID use at presentation with} subsequent mortality (Fig 2)

Of the patients admitted with ulcer bleeding, $288(59 \%)$ had used NSAIDs within the three months before admission compared with 199 non-users. During the follow up period there were $87(30 \%)$ deaths in those originally using NSAIDs and $55(28 \%)$ deaths in non-users.

TABLE IV Late death rates after peptic ulcer bleeding by sex, age, time after admission, and main cause

\begin{tabular}{|c|c|c|c|c|}
\hline & Observed & Expected & $O / E$ & $(95 \% C L)$ \\
\hline \multicolumn{5}{|c|}{ By all causes $(001-999)^{\star}$} \\
\hline Both sexes & 142 & $81 \cdot 5$ & $1 \cdot 74$ & $(1.5$ to $2 \cdot 1)$ \\
\hline Men & 84 & $47 \cdot 2$ & $1 \cdot 78$ & $(1 \cdot 4$ to $2 \cdot 2)$ \\
\hline Women & 58 & $34 \cdot 3$ & 1.69 & $(1 \cdot 3$ to $2 \cdot 2)$ \\
\hline \multicolumn{5}{|l|}{ Age $(y)$} \\
\hline $60-64$ & 4 & $2 \cdot 1$ & 1.93 & $(0.5$ to 4.9$)$ \\
\hline $65-74$ & 50 & $18 \cdot 2$ & $2 \cdot 74$ & $(2 \cdot 0$ to $3 \cdot 6)$ \\
\hline $75-84$ & 66 & $39 \cdot 3$ & $1 \cdot 68$ & $(1 \cdot 3$ to $2 \cdot 1)$ \\
\hline $85+$ & 22 & 21.9 & 1.00 & $(0.6$ to 1.5$)$ \\
\hline \multicolumn{5}{|c|}{ Time since admission } \\
\hline$<1$ year & 51 & $26 \cdot 6$ & 1.91 & $(1.5$ to 2.5$)$ \\
\hline $1-3$ years & 62 & $39 \cdot 9$ & 1.55 & $(1 \cdot 2$ to $2 \cdot 0)$ \\
\hline $3-6$ years & 29 & $15 \cdot 0$ & 1.93 & ( $1 \cdot 3$ to $2 \cdot 8)$ \\
\hline \multirow{2}{*}{\multicolumn{5}{|c|}{ By main causes }} \\
\hline & & \multicolumn{3}{|c|}{ All vascular diseases $(390-459)$} \\
\hline $\mathrm{M}$ & 31 & $22 \cdot 4$ & 1.38 & $(0.9$ to $2 \cdot 0)$ \\
\hline $\mathrm{F}$ & 18 & $17 \cdot 4$ & 1.03 & $(0.6$ to 1.6$)$ \\
\hline \multicolumn{5}{|c|}{ Respiratory disease $(460-519)$} \\
\hline $\mathbf{M}$ & 12 & $6 \cdot 7$ & 1.79 & $(0.9$ to 3.1$)$ \\
\hline $\mathrm{F}$ & 16 & $4 \cdot 2$ & $3 \cdot 83$ & $(2 \cdot 2$ to $6 \cdot 2)$ \\
\hline \multicolumn{5}{|c|}{ All neoplasms $(140-208)$} \\
\hline M & 23 & $12 \cdot 8$ & $1 \cdot 80$ & $(1 \cdot 1$ to $2 \cdot 7)$ \\
\hline $\mathrm{F}$ & 11 & $6 \cdot 9$ & 1.59 & $(0.8$ to 2.9$)$ \\
\hline
\end{tabular}

^International Classification of Diseases 9th revision code.

\section{Gastric cancer deaths}

Five of the patients with bleeding ulcers subsequently developed gastric cancer, which was not diagnosed during the original admission. In one subject the diagnosis was made from biopsy specimens taken at endoscopy three months after the index admission. The patient had a successful curative resection for early gastric cancer. Only two of the remaining four subjects underwent follow up endoscopy, however, and the time to eventual diagnosis ranged from 15-33 months (Table VI). These patients all died as a result of their disease.

\section{Discussion}

We have found a significant reduction in life expectancy in patients aged 60 or over who survived hospital admission for acute peptic ulcer bleeding, when compared with matched community controls or with expected mortality according to national death rates. We have chosen to concentrate on comparisons based on national mortality for two reasons. Firstly, death rates in Nottingham are close to the national average, the standardised death ratio for Nottingham in 1991 being $101 .{ }^{11}$ Secondly, so doing avoids problems of both control selection and chance imbalances resulting from small numbers when comparing mortality by cause. As some of the community controls were selected on the basis of their records being available in the record store, the records of patients unwell and undergoing active treatment and the records of those already in nursing homes may not have been available in the store for selection. In addition 
TABLE V Characteristics and course of patients in whom gastric cancer was subsequently diagnosed after upper gastrointestinal haemorrhage

\begin{tabular}{|c|c|c|c|c|c|}
\hline \multirow{4}{*}{$\begin{array}{l}\text { Sex } \\
\text { Age at admission } \\
\text { OGD findings } \\
\text { Biopsies at first OGD } \\
\text { Follow up OGD } \\
\text { Outcome } \\
\text { Time until cancer } \\
\text { diagnosis } \\
\text { Final diagnosis }\end{array}$} & \multicolumn{5}{|l|}{ Patients } \\
\hline & $\begin{array}{l}\text { F } \\
80 \\
\text { GU lesser curve } \\
\text { Yes } \\
\text { Healed } \\
\text { Discharge }\end{array}$ & $\begin{array}{l}\text { F } \\
78 \\
\text { GU lesser curve } \\
\text { No } \\
\text { Scar } \\
\text { Referred, surgery }\end{array}$ & $\begin{array}{l}\text { F } \\
80 \\
\text { GU lesser curve } \\
\text { No } \\
\text { Scar } \\
\text { Discharge }\end{array}$ & $\begin{array}{l}\text { M } \\
68 \\
\text { GU lesser curve } \\
\text { Yes } \\
\text { Not done } \\
\text { Discharge }\end{array}$ & $\begin{array}{l}\text { F } \\
73 \\
\text { ?DU } \\
\text { No } \\
\text { Not done } \\
\text { Discharge }\end{array}$ \\
\hline & & & & & \\
\hline & $\begin{array}{l}\text { Gastric cancer } \\
\text { clinically (no PM) } \\
\text { Died } 1 \text { month }\end{array}$ & $\begin{array}{l}\text { Early gastric cancer, } \\
\text { curative } \\
\text { Alive } 6 \text { years }\end{array}$ & $\begin{array}{l}\text { Inoperable gastric } \\
\text { cancer } \\
\text { Died } 3 \text { months }\end{array}$ & $\begin{array}{l}\text { Gastric cancer, } \\
\text { palliative surgery } \\
\text { Died } 7 \text { months }\end{array}$ & $\begin{array}{l}\text { Gastric cancer, } \\
\text { unfit for surgery } \\
\text { Died } 3 \text { months }\end{array}$ \\
\hline
\end{tabular}

$\mathrm{GU}=$ gastric ulcer; $\mathrm{DU}=$ duodenal ulcer; $\mathrm{OGD}=$ oesophageal duodenoscopy; $\mathrm{PM}=$ postmortem examination.

general practitioners advised against approaching a small number of controls because of serious illness. We suspect that the selection bias introduced accounts for the lower mortality of the community group when compared with national mortality. It might be thought that comparing mortality with that of other acute medical admissions would be more appropriate. This would have the merit of matching for any general or non-specific ill health contributing to admission for bleeding peptic ulcer. As most acute medical admissions are for cardiorespiratory disease, however, there would be serious confounding from the late mortality attributable to the controls' own diseases. For this reason we chose not to follow up the hospital controls recruited for the original case control study. ${ }^{5}$

The increase in mortality occurred in both sexes and was not accounted for by deaths in the very elderly, neither were the excess deaths confined to the early period following discharge from hospital. The increase was due mainly to an excess of deaths from cancer (14), respiratory (17), and cardiovascular disease (9), which accounted for 40 of 60 excess deaths. Deaths from subsequent ulcer complications were uncommon accounting for only eight $(13 \%)$ of the excess deaths. As in previous studies ${ }^{12-16}$ NSAID use at initial presentation was associated with an increased risk of peptic ulcer bleeding at that time. NSAID use at this point, however, was not associated with

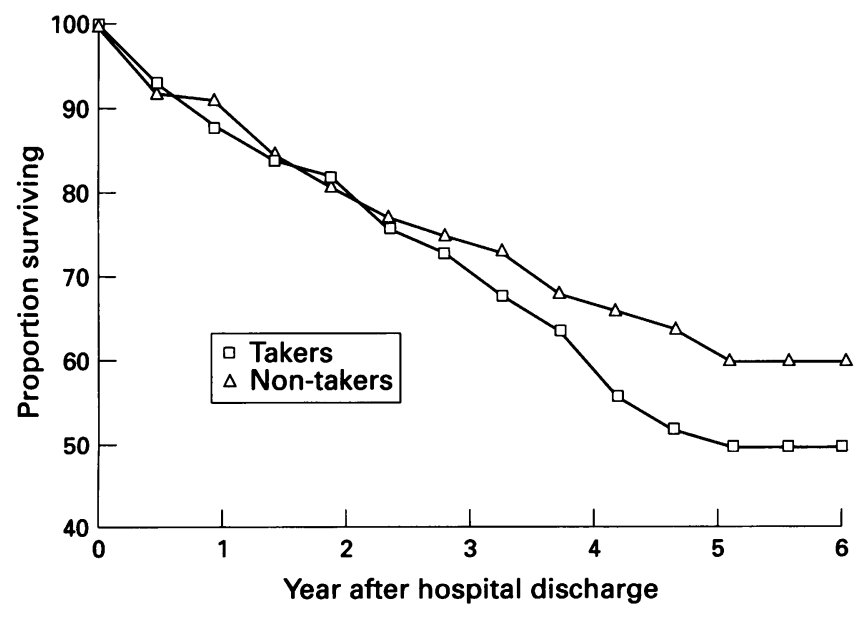

Takers/Deaths $\quad 288 / 35 \quad 269 / 17 \quad 217 / 16 \quad 134 / 10 \quad 76 / 8 \quad 36 / 1 \quad 7 /-$

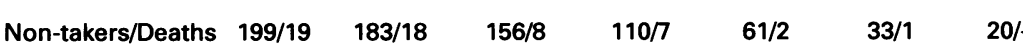
Figure 2: Actuarial survival cures of 288 NSAID takers compared with 199 non-takers. a reduction in subsequent life expectancy when compared with patients not taking these drugs at the time of admission (Fig 2). Patients who were using NSAIDs before their peptic bleed were less likely to be taking antacids or antiulcer treatment than non-users before their original admission with gastrointestinal bleeding. This is compatible with evidence suggesting that NSAID users may suffer fewer dyspeptic symptoms from their ulcers than non-users. ${ }^{17-19}$

Overall patients were receiving more drug treatment before their admission than community controls. Corticosteroids, which are thought to exacerbate the gastrointestinal toxicity of NSAIDs, ${ }^{20}$ and anticoagulants were significantly more commonly taken by patients than controls. Our study also found an association between upper gastrointestinal bleeding and diuretic use but an inverse association with $\beta$ blockade, or antiarrythmic treatment. An association between peptic ulceration and cardiovascular disease has long been recognised although the possible mechanism of interaction remains obscure. ${ }^{2122}$ The higher rate of diuretic prescribing in patients might be explained by the presence of underlying cardiovascular or other disease (M Langman, personal communication). Another possibility is that diuretics themselves promote peptic ulcer haemorrhage. Ethacrynic acid (but not frusemide) use has previously been significantly associated with gastrointestinal bleeding. ${ }^{23}$ The increase in diuretic use in patients admitted with bleeding ulcers that we found, particularly in those using NSAIDs, would support the suggestion that diuretics might exacerbate the ulcerogenic effects of NSAIDs. Further work will be required to find out if diuretics do indeed promote gastroduodenal haemorrhage.

The increased subsequent mortality from cancer, respiratory, and cardiovascular disease suggests that the original admission for peptic ulcer bleeding may be a marker of disease in other systems. Another possibility is that haemorrhage from existing ulcer itself is precipitated by the presence of coexistent disease. Many previous studies have shown that a substantial proportion of the early mortality after upper gastrointestinal bleeding can be attributed to concomitant disease and it seems that this may also be contributing to an increase in longterm mortality. ${ }^{1224-26}$

An increase in mortality from stroke (ICD9 430-438) might have been expected given the association between cerebral thrombosis 
and smoking. The association with current smoking was not strong (Table II), however, and the numbers are not large enough to exclude a moderately increased risk. Furthermore, a recent analysis of longterm mortality after elective surgery for duodenal ulcer found no increase in circulatory disease mortality despite a $33 \%$ increased mortality from smoking related cancers. ${ }^{27}$

Few subsequent deaths were caused by recurrent peptic ulcer complications. Of the eight deaths identified as resulting from ulcer complications only five would have been recognised as such from the underlying cause given on the death certificate. Another recent study has also reported a low rebleeding rate $(9 \%)$ within two years of upper gastrointestinal haemorrhage. ${ }^{28}$ These complication rates are low when compared with rates in previous studies. Smart and Langman followed up an early cohort of patients with bleeding gastric ulcers identified between 1971 and 1976 in the Nottingham hospitals and found a cumulative ulcer haemorrhage, perforation or related death rate of $19 \%$, recurrence rates tending to occur within the first three years of follow up and more commonly in women. ${ }^{29}$ Earlier studies have reported complication rates of $30 \%$ for bleeding gastroduodenal ulcers ${ }^{30}$ and $22 \%$ for medical treatment of bleeding duodenal ulcers. ${ }^{31}$ These studies were performed before the introduction of $\mathrm{H}_{2}$ antagonists for ulcer healing and prophylaxis therapy. Although a healthier population with a reduction in smoking may account for some of these differences the low peptic ulcer related death and recurrent complication rates in our study may reflect the widespread use of prolonged antiulcer treatment that these subjects received after hospital discharge. ${ }^{32}$ At the time of any subsequent ulcer complication only a few $(17 \%)$ of these patients were taking antiulcer treatment.

In four cases there was a considerable delay in the diagnosis of gastric carcinoma despite the likelihood that the neoplasms were the probable cause of bleeding at the original presentation. This reiterates the importance of follow up endoscopy and biopsy in all subjects presenting with bleeding gastric ulcers.

In conclusion patients admitted with acute peptic ulcer bleeding have a reduced longterm life expectancy. NSAID use at the time of original admission did not influence the subsequent death rates nor was the excess mortality particularly related to recurrent peptic ulcer complications. Peptic ulcer complications were uncommon and less than reported in previous decades, which may reflect the widespread use of secondary prophylactic antiulcer treatment.

This study would not have been possible without the MRC's support of the original case control study (project grant SPG 86/95895).
1 Allan R, Dykes PW. A study of the factors influencing mortality rates from gastrointestinal haemorrhage. $Q \mathcal{F} \mathrm{Med}$ 1976; 45: 533-50.

2 Hunt PS, Hansky K, Korman MG. Mortality in patients with haematemesis and melaena; a prospective study. BMF 1979; i: 1239-40.

3 Barer D, Ogilvie A, Henry D, Dronfield M, Coggon D, French $\mathrm{S}$, et al. Cimetidine and tranexamic acid in the treatment of acute upper gastrointestinal bleeding. $N \mathrm{Engl}$ f Med 1983; 308: 1571-5.

4 Daneshmend TK, Hawkey CJ, Langman MJS, Logan RFA, Long RG, Walt RP. Omeprazole versus placebo for acute upper gastrointestinal bleeding: randomised double blind upper gastrointestinal bleeding: random

5 Langman MJS, Weil J, Wainwright P, Lawson DH, Rawlins M, Logan RFA, et al. Risks of bleeding peptic ulcer associated with individual non-steroidal anti-inflammatory drugs. Lancet 1994; 343: 1075-8.

6 Breslow NE, Day NE. Statistical methods in cancer research. Vol I. The analysis of case control studies. Lyon: International agency for research on cancer scientific publications, 1980

7 Office of Population Censuses and Surveys. Mortality statistics - cause. England and Wales 1989. London: HMSO, 1991: Series DH2, No 16.

8 Coleman M, Douglas A, Herman C, Peto J. Cohort study analysis with a Fortran computer program. Int $\mathcal{f}$ Epidemiol 1986; 13: 134-7.

9 Cox DR. Regression models and life-tables. Fournal of Royal Statistical Society 1972; 34: 187-220.

10 Statistics and Epidemiology Research Corporation and Cytel Software Corporation. Epidemiological graphics,estimation and testing (EGRET). Seattle: Statistics and Epidemiology Research Corporation, 1991.

11 Annual report of the Director of Public Health. 1994: Nottingham Health District.

12 Somerville K, Faulkner G, Langman MJS. Non-steroidal anti-inflammatory drugs and bleeding peptic ulcer. Lancet 1986; i: $462-4$.

13 Carson JL, Strom BL, Soper KA, West SL, Morse ML. The association of non-steroidal anti-inflammatory drugs with association of non-steroidal anti-inflammatory drugs with upper gastrointe

14 Laporte J-R, Carne X, Vidal X, Moreno V, Juan J. Upper gastrointestinal bleeding in relation to previous use of analgesics and non-steroidal anti-inflammatory drugs. Lancet 1991; 337: 85-9.

15 Griffin MR, Ray WA, Schaffner W. Non-steroidal antiinflammatory drug use and death from peptic ulcer in elderly persons. Ann Intern Med 1988; 109: 359-63.

16 Gabriel SE, Jaakkimainen L, Bombardier C. Risk for serious gastrointestinal complications related to use of nongastrointestinal complications related to use of nonIntern Med 1991; 115: 787-96.

17 Skander MP, Ryan FP. Non-steroidal anti-inflammatory drugs and pain free peptic ulceration in the elderly. $B M \mathcal{F}$ 1988; 297: 833-4.

18 Shallcross TM, Heatley RV. Effect of non steroidal antiinflammatory drugs on dyspeptic symptoms. BMF 1990; 300: 368-9.

19 Armstrong CP, Blower AL. Non-steroidal anti-inflammatory drugs and life threatening complications of peptic ulceration. Gut 1987; 28: 527-32.

20 Piper JM, Ray WA, Daugherty JR, Griffin MR. Corticosteroid use and peptic ulcer disease: role of nonsteroidal anti-inflammatory drugs. Ann Intern Med 1991; 114: $735-40$.

21 Editorial. Cardiovascular disease and peptic ulcer. $B M \mathcal{F}$ 1974; 2: 760-1.

22 Langman MJS, Cooke AR. Gastric and duodenal ulcer and their associated diseases. Lancet 1976; i: 680-3.

23 Jick $H$. Effects of aspirin and acetaminophen in gastrointestinal haemorrhage. Arch Intern Med 1981; 141: 316-21.

24 Katschinski BD, Logan RFA, Davies J, Langman MJS Audit of mortality in upper gastrointestinal haemorrhage. Postgrad Med $¥$ 1989; 65: 913-7.

25 Logan RFA, Finlayson NDC. Death in acute upper gastrointestinal bleeding. Lancet 1976; i: 1173-5.

26 Clason AE, Macleod DAD, Elton RA. Clinical factors in the prediction of further haemorrhage or mortality in acute prediction of further haemorrhage or mortality in acute

27 Macintyre IMC, O'Brien F. Death from malignant disease after surgery for duodenal ulcer. Gut 1994; 35: 451-4.

28 O'Keffe PA, Loizou LA, Grigg D. Late follow up in patients with peptic ulcer haemorrhage. Gut 1989; 30: A1488.

29 Smart HL, Langman MJS. Late outcome of bleeding gastric ulcers. Gut 1986; 27: 926-8.

30 Borland JL, Hancock WR, Borland JL. Recurrent upper gastrointestinal haemorrhage
Gastroenterology 1967; 52: 631-7

31 Harvey RF, Langman MJS. The late results of medical and surgical management for bleeding duodenal ulcers. $Q \mathcal{F}$ Med 1970; 39: 539-47.

32 Hudson N, Faulkner G, Smith SJ, Hawkey CJ, Logan RFA. Morbidity and management in patients surviving upper gastrointestinal bleeding associated with non steroidal anti-inflammatory drugs. Gut 1992; 33 (suppl 2): S39. 